\title{
p39 Is Responsible for Increasing Cdk5 Activity during Postnatal Neuron Differentiation and Governs Neuronal Network Formation and Epileptic Responses
}

\author{
Wenqi Li, ${ }^{1 \star}$ Megan E. Allen, ${ }^{1 *}$ Yanfang Rui, ${ }^{2}$ Li Ku, ${ }^{1}$ Guanglu Liu, ${ }^{1}$ Andrew N. Bankston, ${ }^{1}$ James Q. Zheng, ${ }^{2}$ \\ and $\odot$ Yue Feng ${ }^{1}$ \\ Departments of ${ }^{1}$ Pharmacology and ${ }^{2}$ Cell Biology, Emory University School of Medicine, Atlanta, Georgia 30322
}

Two distinct protein cofactors, p35 and p39, independently activate Cyclin-dependent kinase 5 (Cdk5), which plays diverse roles in normal brain function and the pathogenesis of many neurological diseases. The initial discovery that loss of p35 impairs neuronal migration in the embryonic brain prompted intensive research exploring the function of p35-dependent Cdk5 activity. In contrast, p39 expression is restricted to the postnatal brain and its function remains poorly understood. Despite the robustly increased Cdk5 activity during neuronal differentiation, which activator is responsible for enhancing Cdk5 activation and how the two distinct activators direct Cdk5 signaling to govern neuronal network formation and function still remains elusive. Here we report that p39, but not p35, is selectively upregulated by histone acetylation-mediated transcription, which underlies the robust increase of Cdk 5 activity during rat and mouse neuronal differentiation. The loss of $\mathrm{p} 39$ attenuates overall $\mathrm{Cdk} 5$ activity in neurons and preferentially affects phosphorylation of specific $\mathrm{Cdk} 5$ targets, leading to aberrant axonal growth and impaired dendritic spine and synapse formation. In adult mouse brains, p39 deficiency results in dysregulation of $\mathrm{p} 35$ and Cdk 5 targets in synapses. Moreover, in contrast to the proepileptic phenotype caused by the lack of p35, p39 loss leads to deficits in maintaining seizure activity and induction of immediate early genes that control hippocampal excitability. Together, our studies demonstrate essential roles of p39 in neuronal network development and function. Furthermore, our data support a model in which Cdk5 activators play nonoverlapping and even opposing roles to govern balanced Cdk5 signaling in the postnatal brain.

Key words: axon development; Cdk5 activators; Cyclin-dependent kinase 5; dendritic spine; phosphorylation; seizure

Significance Statement

Neuronal network development requires tightly regulated activation of Cyclin-dependent kinase 5 (Cdk5) by two distinct cofactors, $\mathrm{p} 35$ and p39. Despite the well-known p35-dependent Cdk5 function, why postnatal neurons express abundant $\mathrm{p} 39$ in addition to $\mathrm{p} 35$ remained unknown for decades. In this study, we discovered that selective upregulation of p39 is the underlying mechanism that accommodates the increased functional requirement of Cdk5 activation during neuronal differentiation. In addition, we demonstrated that $\mathrm{p} 39$ selectively directs $\mathrm{Cdk} 5$ to phosphorylate protein substrates essential for axonal development, dendritic spine formation, and synaptogenesis. Moreover, our studies suggest opposing roles of p 39 and p35 in synaptic Cdk5 function and epileptic responses, arguing that cooperation between Cdk5 activators maintains balanced Cdk5 signing, which is crucial for postnatal brain function.

\section{Introduction}

Molecular pathways that play intricate roles in the brain are often regulated by orthologous factors that harbor similar biochemical properties yet serve differential biological functions. One such example is Cyclin-dependent kinase $5(\mathrm{Cdk} 5)$, a proline-directed

\footnotetext{
anti-MAP1B antibody; Dr. Li-Huei Tsai and Dr. James Bibb for providing the $p 39^{-/-}$mice; and Dr. Asheebo Rojas for advice on KA-induced seizure.

The authors declare no competing financial interests.

*W.L. and M.E.A. contributed equally to this study.

Correspondence should be addressed to Dr. Yue Feng, Department of Pharmacology, Emory University School of Medicine, 1510 Clifton Road, Atlanta, GA 30322.E-mail:yfeng@emory.edu.

DOI:10.1523/JNEUROSCI.1155-16.2016

Copyright $\odot 2016$ the authors $\quad 0270-6474 / 16 / 3611283-12 \$ 15.00 / 0$

Author contributions: W.L., M.E.A., Y.R., J.Q.Z., and Y.F. designed research; W.L., M.E.A., Y.R., L.K., G.L., and A.N.B. performed research; W.L., M.E.A., Y.R., L.K., and Y.F. analyzed data; W.L., M.E.A., and Y.F. wrote the paper.

This work was supported by National Institutes of Health R01s NS093016 and NS070526, and Emory University Research Committee Award to Y.F. M.E.A. was supported by National Institutes of Health Training Grant 5T32GM008367. W.L. was supported by the FraXa postdoctoral fellowship. We thank Dr. Itzhak Fischer for the
} 
serine/threonine kinase that controls neuronal migration in the embryonic brain, neuronal circuitry formation in the neonate, and neurotransmitter release in the adult (Su and Tsai, 2011). Two distinct protein cofactors, called p35 and p39, display comparable efficiency for activating Cdk5 in vitro and can independently activate Cdk5 in vivo (Ko et al., 2001; Yamada et al., 2007). Although Cdk5 is ubiquitously expressed, activity of the kinase is limited by the available amount of p 35 and p 39 within a cell, both of which are rapidly degraded upon Cdk5 activation (Minegishi et al., 2010). Exacerbation and/or deficiency of Cdk5 activity have been found in a rapidly growing list of neurological diseases ( $\mathrm{Su}$ and Tsai, 2011), indicating that precise control of Cdk5 activity is crucial for normal brain function. Nonetheless, how the expression of Cdk5 activators is regulated to govern Cdk5 function remains poorly understood.

During embryonic brain development, the essential function of Cdk 5 in cortical layering is primarily mediated by $\mathrm{p} 35$, whereas p39 is scarcely expressed until after birth (Tsai et al., 1994; Chae et al., 1997; Humbert et al., 2000a; Ko et al., 2001). In the postnatal brain, both p35 and p39 are abundantly expressed in neurons and can be detected within neuronal arbors and synaptic terminals (Nikolic et al., 1996; Humbert et al., 2000a). However, despite the intensive investigation of p35-dependent Cdk5 signaling, p39 function is understudied and therefore poorly understood, partly due to the lack of an overt phenotype in $p 39^{-/-}$mice (Ko et al., 2001). Although p39-dependent Cdk5 activity was recently found to be essential for advancing early differentiation of oligodendrocytes (OLs) and myelin repair (Bankston et al., 2013), why postnatal neurons express abundant p39 in addition to p35 still remains a mystery. The complexity of Cdk5 function in controlling dendritic spine density and synaptic plasticity (Fu et al., 2007; Hawasli et al., 2007; Lai et al., 2012) raises the intriguing question of whether p35 and p39 may differentially direct the diverse roles of Cdk5 in neurons. Importantly, during neonatal neuron development, Cdk5 activity is markedly increased (Tsai et al., 1994), which is essential to advance axonal and dendritic arbor formation (Ye et al., 2012; Ng et al., 2013). However, which of the Cdk5 activators is responsible for increasing Cdk5 activity in postnatal neurons is not understood. Moreover, how the two distinct activators cooperate to govern synaptic Cdk5 function in the adult brain remains unknown.

In this study, we identify molecular mechanisms that selectively upregulate $\mathrm{p} 39$, but not $\mathrm{p} 35$, during neuronal differentiation, leading to increased Cdk5 activity in the postnatal brain. Loss of p39 in neurons not only attenuates overall Cdk5 activity but also differentially affects Cdk5 targets critical for neuronal network assembly, which results in abnormalities in axonal growth and dendritic spine formation. Moreover, $p 39^{-/-}$synapses harbor dysregulation of $\mathrm{p} 35$ and aberrant phosphorylation of Cdk5 targets. Finally, in contrast to the increased seizure susceptibility of the $p 35^{-/-}$mice (Chae et al., 1997; Patel et al., 2004), p39 $9^{-1-}$ mice display ameliorated behavioral and molecular responses upon pharmacologically induced seizure. These studies demonstrate that $\mathrm{p} 39$-dependent Cdk5 activation plays essential roles in postnatal neurons, and suggest that a functional balance between Cdk5 activators is crucial for normal Cdk5 signaling in the brain.

\section{Materials and Methods}

Animal treatment and behavior analysis. The $p 39^{-1-}$ mouse colony (courtesy of Dr. Li-Huei Tsai and Dr. James Bibb) was previously described (Ko et al., 2001). Animal treatment was performed in accordance
Table 1. The number of mice used for qPCR analysis of each immediate early gene

\begin{tabular}{|c|c|c|c|c|c|c|}
\hline Primer & $\begin{array}{l}\text { Mock, } \\
\text { Wt }\end{array}$ & $\begin{array}{l}\text { Mock, } \\
\text { p39-- }\end{array}$ & $\begin{array}{l}80 \mathrm{~min}, \\
\mathrm{Wt}\end{array}$ & $\begin{array}{l}80 \text { min, } \\
p 39^{-\prime-}\end{array}$ & $\begin{array}{l}180 \mathrm{~min}, \\
\mathrm{Wt}\end{array}$ & $\begin{array}{l}180 \mathrm{~min}, \\
\text { p39- }\end{array}$ \\
\hline$c-$ fos & 7 & 5 & 7 & 4 & 9 & 8 \\
\hline ARC & 7 & 4 & 3 & 4 & 9 & 9 \\
\hline BDNF & 7 & 5 & 3 & 4 & 8 & 10 \\
\hline
\end{tabular}

with National Institutes of Health regulations under approval of the Emory University Institutional Animal Care and Use Committee.

Pharmacological seizure induction and behavioral analysis. Six- to 8-week-old male Wt (C57BL/6) and $p 39^{-/-}$mice were subjected to intraperitoneal injection of kainic acid (KA, $25 \mathrm{mg} / \mathrm{kg}$ ) or $1 \times \mathrm{PBS}$ (mock). Seizure activity was monitored for up to $180 \mathrm{~min}$. A modified Racine scale was used as described previously (Rojas et al., 2014). Duration of status epilepticus (SE, defined as continued seizure at or above grade 5) and latency to SE (time elapsed from injection until grade 5) were measured. The number of mice used for qPCR analysis of each immediate early gene in Figure 7 is indicated in Table 1.

Primary neuron culture and transfection. Primary rat cortical and hippocampal neurons were prepared from E18 brains, whereas $\mathrm{Wt}$ and p39 $9^{-1-}$ mouse hippocampal neurons were raised using P0 brains (Banker and Cowan, 1977). Sequential transfections of p39 siRNA (Bankston et al., 2013) or control siRNA were performed on DIV3 and DIV4 using lipofectamine (Invitrogen), and neurons were harvested at DIV5 for a Cdk5 kinase assay. For dendritic spine analysis, rat hippocampal neurons were transfected with eGFP and p39 siRNA with or without a rescue plasmid using the Calphos calcium phosphate transfection kit (Clontech) on DIV13 as described previously (Fan et al., 2011) and processed at DIV16 for immunostaining and confocal imaging.

Cdk5 activity assay. The Cdk5 kinase assay was performed as previously described (Bankston et al., 2013). Briefly, primary cultured rat cortical neurons transfected with sip39 or sictrl (Invitrogen) were lysed in a buffer containing $0.1 \% \mathrm{NP}-40,50 \mathrm{~mm}$ Tris- $\mathrm{HCl}, \mathrm{pH} 7.5,25 \mathrm{~mm} \mathrm{NaCl}$, $1 \mathrm{~mm}$ EDTA, $5 \mathrm{~mm}$ sodium orthovanadate, $5 \mathrm{~mm}$ sodium fluoride, and protease inhibitors. Lysates containing equal amounts of total protein in each sample were incubated with $2.5 \mu \mathrm{g}$ of anti-Cdk5 antibody (Millipore) for immunoprecipitation of $\mathrm{Cdk} 5$ complexes. The complexes were washed and suspended in a kinase buffer (20 mM MOPS, pH 7.0, $5 \mathrm{~mm}$ $\mathrm{MgCl}_{2}, 100 \mu \mathrm{M}$ EDTA, $100 \mu \mathrm{M}$ EGTA, and protease inhibitors) and incubated with $100 \mathrm{ng} / \mu$ l histone $\mathrm{H} 1$ in the presence of $25 \mu \mathrm{M}$ cold ATP and $10 \mu \mathrm{Ci} \gamma^{-}{ }^{32} \mathrm{P}-\mathrm{ATP}$ at $30^{\circ} \mathrm{C}$ for $30 \mathrm{~min}$. Proteins from each reaction were resolved by SDS-PAGE and transferred to PVDF membranes. Phosphorylation of Histone $\mathrm{H} 1$ was detected by autoradiography and immunoprecipitated Cdk5 was detected by immunoblot on the same membrane for quantitative analysis.

Dendritic spine analysis. Images of eGFP-transfected neurons were captured using a Nikon C1 laser-scanning confocal system based on a Nikon inverted microscope (TE300), with a $60 \times$ N.A.1.4 Plan Fluor oil-immersion objective. To image all of the dendritic branches at different focusing planes of a dendritic segment, $Z$-stacks of images of eGFPexpressing neurons were acquired and converted to $2 \mathrm{D}$ images by maximal intensity projection. Dendritic spines were defined as described previously (Hotulainen et al., 2009) and analyzed using ImageJ (National Institutes of Health) (Fan et al., 2011). For identification of mature and functional spines, neurons were subjected to immunostaining of SV2 and PSD95 as presynaptic and postsynaptic markers, respectively (Perez de Arce et al., 2010), followed by staining with a Texas Redconjugated goat antibody. Secondary or tertiary dendritic segments were chosen to ensure a uniform population. Spine numbers were counted on the entire dendritic segment and spine density per unit of dendritic segment length were manually calculated. Experimenters were blind to treatment during acquisition and analysis. All experiments were from a minimum of three independent cultures and at least six transfected neurons per dish.

For in vivo spine imaging, the Thy1-YFP- $H$ transgenic mice (The Jackson Laboratory) were crossed with $p 39^{-/-}$mice. Coronal cryostat sections were prepared form fixed brains of YFP- $p 39^{-1-}$ and YFP-Wt 
Table 2. Primers used for qRT-PCR analysis

\begin{tabular}{llc}
\hline Name & Forward $5^{\prime}-3^{\prime}$ & Reverse $5^{\prime}-3^{\prime}$ \\
\hline p39 & AACCTGGTGTTCGTGT & AGATCTCGTTGCCCATG \\
& ACCTGCT & TAGGAGT \\
p35 & AACAGCAAGAACGCCAAG & ATGTTGCTCTGGTAGCTG \\
& GACAAG & CTGTTG \\
c-fos & AGAAGGGGCAAAGTA & CGCAGACTTCTCATCT \\
& GAGCAG & TCAAGT \\
ARC & CCTACAGAGCCAGGAG & CTTCAGGAGAAGAGAGG \\
& AATGA & ATGGT \\
BDNF & GCCGCAAACATGTCTATGA & TTGGCCTTTGGATACC \\
& GGGTT & GGGACTTT \\
\hline
\end{tabular}

littermates at the age of P22-P25. YFP-labeled apical dendritic branches of layer $\mathrm{V}$ pyramidal neurons were imaged with $488 \mathrm{~nm}$ laser, using a $63 \times$ objective $(63 \times / 1.4$ oil $)$ with $3 \times$ digital zoom as previously described (Maynard and Stein, 2012). Confocal fluorescence image stacks of $512 \times 512$ pixels were obtained. Optical sections were scanned at increments of $0.4 \mu \mathrm{m}$ with a speed of $2.40 \mu \mathrm{s} /$ pixel. Spine counts were obtained from $50-90 \mu \mathrm{m}$ of randomly selected primary dendritic segments and 20-30 $\mu \mathrm{m}$ tuft dendritic segments. Primary dendritic segments were selected between 100 and $200 \mu \mathrm{m}$ from the cell body ("middle regions"), and tuft dendritic segments were selected within 60 $\mu \mathrm{m}$ from the pial surface as previously described (Stuss et al., 2012). Spines projecting above and below the dendrite in the $z$-axis were not counted. In regions of high spine density, potentially overlapping spines were identified by vertically scrolling through confocal $Z$-stacks. Because of the difficulty of unequivocally distinguishing filopodia from long thin spines, protrusions $>4 \mu \mathrm{m}$ were excluded. For each genotype, 3 animals were used with 25-29 segments analyzed per animal for spine count and density calculation.

Axon length and branch measurement in culture. At DIV4, cultured mouse hippocampal neurons were subjected to dual immunofluorescent staining of TAU-1 and MAP2. Confocal imaging was performed, and single-axon neurons were selected for quantification. Axons were traced with the "Simple Neurite Tracer" plugin (ImageJ, National Institutes of Health). Length and branch number of every axon were quantified using the ImageJ software (Dent et al., 2004).

Analysis of mossy fiber (MF) tracts. Cryostat brain sections from $p 39^{-1-}$ and Wt mice were subjected to parallel immunofluorescent staining for calbindin. Fluorescent signals from the MF tract were captured and quantified as previously described (Bagri et al., 2003).

Quantitative analysis of RNA. Total RNA was extracted with Trizol (Invitrogen) and reverse transcribed using random primers (Promega) and the Quantitect Reverse Transcription Kit with DNase treatment (QIAGEN). qPCR was performed using Quanta SYBR Green FastMix for iQ kit (20117, Quanta) in a iQ5 Multicolor Real-time PCR detection System (Bio-Rad). Relative quantification of each mRNA was determined based on the standard curve generated using corresponding primers, and all relative concentrations were normalized to the expression of $\beta$-actin as an internal control. Primers used for qRT-PCR analysis are listed in Table 2.

Chromatin immunoprecipitation (ChIP). For tissue ChIP, hippocampi were dissected from $\mathrm{Wt}$ and $p 39^{-/-}$mice at the indicated ages, minced, and fixed in $3.4 \%$ formaldehyde $1 \times$ PBS buffer in the presence of protease inhibitors for $10 \mathrm{~min}$. For cultured neurons, formaldehyde was added to the media to a concentration of 3.4\% and incubated for $10 \mathrm{~min}$ at $37^{\circ} \mathrm{C}$. Each sample was washed with $0.125 \mathrm{M}$ glycine for $5 \mathrm{~min}$ followed by two $1 \times$ PBS washes before being sonicated 4 times in $10 \mathrm{~s}$ intervals. The genomic DNA fragment size in each sample was examined by ethidium bromide-stained agarose gel, and total DNA concentration was determined using a spectrometer. For each sample, lysate containing 50 $\mu \mathrm{g}$ of DNA was subjected to IP using ChIP Assay Kit (Millipore). The 4 $\mu \mathrm{g}$ of antibody to H3K9 (rabbit, Millipore, 07-352) or RNA Polymerase II (rabbit, Santa Cruz Biotechnology, sc-899) or IgG control was used in the corresponding ChIP. Primers used for ChIP-qPCR analysis are listed in Table 3.
Table 3. Primers used for ChIP-qPCR analysis

\begin{tabular}{lll}
\hline Name & Forward 5'-3' & Reverse 5'-3' \\
\hline p39promoter & TGCCAAGGAGAAAGGGTG & TCCAAGCCGCAGTATAGA \\
& CATTTG & AGCCAT \\
p390RF & AACCTGGTGTTCGTGTA & AGATCTCGTTGCCCATGT \\
& CCTGCT & AGGAGT \\
p393' end & ACAGGACTTGGCT & GTTGACTGCGCCA \\
& TTCAC & AATTC \\
p35 promoter & GGGCTGAGAACCATCT & TGTGGCCTTTCGATAG \\
& TGTTT & CTGGG \\
\hline
\end{tabular}

Table 4. Antibodies used for immunoblot and immunofluorescence detections

\begin{tabular}{lllll}
\hline Name & Company & Catalog & Dilution & Method \\
\hline p35 & Cell Signaling Technology & 2680 & $1: 1000$ & IB \\
P39 & Santa Cruz Biotechnology & sc-365781 & $1: 1000$ & IB \\
Cdk5 & Cell Signaling Technology & 2506 & $1: 1000$ & IB \\
$\beta$-actin & Sigma-Aldrich & A5441 & $1: 5000$ & IB \\
WAVE1 & Millipore & MABN503 & $1: 1000$ & IB \\
SMI-31 (p-MAP1B) & Calbiochem & NE1022 & $1: 1000$ & IB \\
1E11 (p-MAP1B) & ENZ0 & ALX-804-168-c100 & $1: 1000$ & IB \\
Total MAP1B & Provided by Dr.IFischer & & $1: 10,000$ & IB \\
pS211-GR & Cell Signaling Technology & 4161 & $1: 1000$ & IB \\
GR & Cell Signaling Technology & 3660 & $1: 1000$ & IB \\
Synapsin la/b & Santa Cruz Biotechnology & Sc-8295 & $1: 1000$ & IB \\
p-Synapsin la/b & Santa Cruz Biotechnology & Sc-12913r & $1: 1000$ & IB \\
SV2 & DSHB & AB_2315387 & $1: 2000$ & IF \\
Tau1 & Millipore & MAB3420 & $1: 200$ & IF \\
MAP2 & Millipore & AB5622 & $1: 2000$ & IF \\
Calbindin & Millipore & AB1778 & $1: 50$ & IF \\
PSD-95 & Thermo Fisher & MA1-045 & $1: 200$ & IF \\
\hline
\end{tabular}

Protein extracts, immunoblot analysis, and antibodies used. Whole-cell lysates from cultured neurons or brain tissues were prepared by sonication as previously described (Bankston et al., 2013). Proteins were separated by SDS-PAGE, and transferred to a PVDF membrane (GE Healthcare). All membranes for phospho-specific antibody detection were blocked for $1 \mathrm{~h}$ in TBST with 5\% BSA and $5 \mathrm{~mm}$ sodium orthovanadate. All other membranes were blocked in PBST with 10\% milk for $1 \mathrm{~h}$. Membranes were incubated with primary antibodies diluted to the concentration indicated below. For phospho-antibody detection, antibodies were diluted in TBST with 3\% BSA and 5 mm sodium orthovanadate. For total protein, primary antibodies were incubated in PBST with $2 \%$ milk. After incubation with HRP-conjugated secondary antibodies, membranes were washed and subjected to chemiluminescence detection. Antibodies used for immunoblot and immunofluorescence detections are listed in Table 4.

Synaptoneurosome (SNS) preparation. SNS preparation was performed essentially as previously described (Soden and Chen, 2010) with brief modifications. Hippocampi from 6-week-old mice were used. Hippocampi from each mouse were homogenized in the HEPES buffer without sucrose and EGTA. Samples were passed first through two $100 \mu \mathrm{m}$ nylon mesh filters, followed by one $5 \mu \mathrm{m}$ SLSV025LS Millipore filter and centrifuged for $15 \mathrm{~min}$ at $3500 \times \mathrm{g}, 4^{\circ} \mathrm{C}$. The pellets containing SNSs were resuspended in the same buffer described above, lysed, and subjected to immunoblot analysis.

Statistical analysis. Error bars indicate SEM. Student's $t$ test was used for two-sample comparisons. For multiple sample comparisons, oneway ANOVA analysis and Tukey post hoc test or two-way ANOVA analysis and Bonferroni's post test were used.

\section{Results}

Histone acetylation-mediated transcription selectively upregulates $\mathbf{p} 39$ during neuronal differentiation

To determine which Cdk5 activator is responsible for the documented increase of Cdk5 activity during neonatal brain develop- 
ment, we examined p35 and p39 protein expression by immunoblot in whole hippocampal tissue lysates. The levels of p39 protein were markedly increased during the first postnatal week (Fig. 1A). In contrast, no increase of p35 was detected on the same immunoblots. Considering the appreciable amounts of $\mathrm{p} 39$ expression in glia (Bankston et al., 2013), we isolated and cultured rat cortical neurons to examine the abundance of Cdk5 activator proteins by immunoblot. A nearly 10 -fold increase of $\mathrm{p} 39$ protein was detected during the first week of differentiation in vitro (DIV) (Fig. 1B), demonstrating the intrinsic ability of brain neurons to upregulate p39. A slight increase of $\mathrm{p} 35$ protein was also detected without statistical significance. A similar fold increase of p39 mRNA was observed during cortical neuron differentiation, whereas p35 mRNA expression was unaltered (Fig. 1C). Despite the low abundance of p39 mRNA than p35 mRNA at the beginning of cortical neuron differentiation, continued p39 upregulation resulted in comparable numbers of p39 and p35 mRNA molecules in each cortical neuron by DIV 15 (Fig. 1D). Both p39 and p35 are labile, and no apparent changes in protein stability of p39 upon blocking protein synthesis were observed during neuronal differentiation (Fig. 1E). Thus, the increase of p39 mRNA is a major mechanism that underlies the selective upregulation of $\mathrm{p} 39$ protein in neonatal neurons. Concurrent with the upregulation of p39, a significant increase in Cdk5 protein expression was also detected (Fig. $1 F$ ), further indicating the increased requirement of Cdk5 function in differentiated neurons.

To investigate whether transcription of p39 is enhanced during neuronal differentiation, we performed a ChIP assay to assess recruitment of RNA polymerase II (Pol II) to the p39 gene during cortical neuron differentiation. Figure $2 A$ depicts the primers used for ChIP-qPCR analysis, which were specific to the promoter, open reading frame, and the polyadenylation site at the $3^{\prime}$ end of the p39 gene. Binding of Pol II to the p39 promoter and the $3^{\prime}$ end, two speed-limiting steps of mRNA biogenesis, was increased at DIV6 compared with DIV1 (Fig. 2B). In addition, treatment with the histone deacetylase inhibitor trichostatin A (TSA) significantly increased p39 mRNA (Fig. 2C), but not p35 mRNA (Fig. 2D). TSA-induced upregulation of p39 was accompanied by increased acetylation on lysine 9 of histone 3 (H3K9), a surrogate marker for histone acetylation mediated transcriptional upregulation (Koch et al., 2007), throughout the p39 gene (Fig. 2E). In contrast, TSA did not induce H3K9 acetylation at the p35 promoter (Fig. $2 F$ ). These data clearly indicate that histone acetylation differentially regulates transcription of p39 and p35 in developing neurons.
B

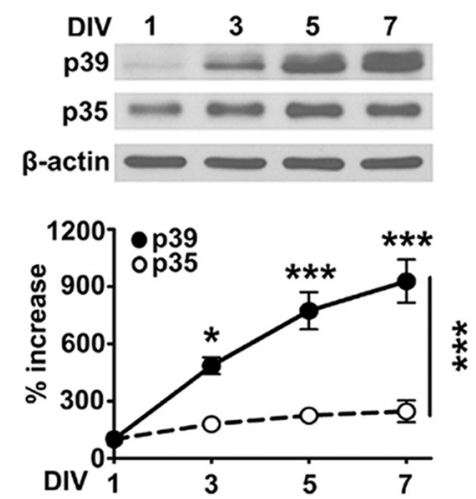

D

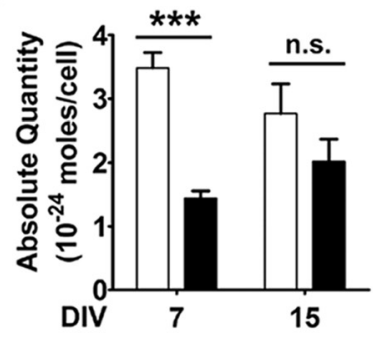

F $\begin{array}{rrrrr}\text { DIV } & 1 & 3 & 5 & 7\end{array}$
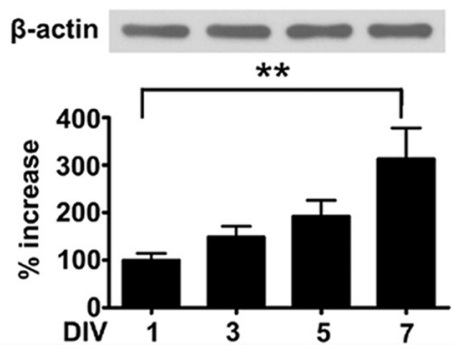

Figure 1. Expression of $\mathrm{p} 35, \mathrm{p} 39$, and $C \mathrm{dk} 5$ during neuronal differentiation. $\boldsymbol{A}$, Immunoblot of $\mathrm{p} 35$ and $\mathrm{p} 39$ protein in mouse hippocampal lysates. $n=4$ mice for postnatal day (PD) 1, 3, and 7, $n=5$ for PD 5. B, Immunoblot of $p 35$ and p39 protein in primary cultured rat cortical neurons. $n=3$ independent cultures for each time-point. $A, B$, Densitometry readings were normalized to $\beta$-actin, and the percentage of increase is graphically displayed underneath the representative immunoblot image. $C$, qRT-PCR analysis of $\mathrm{p} 35$ and $\mathrm{p} 39 \mathrm{mRNA}$ levels in primary rat cortical neurons. The percentage of increase compared with DIV1 is graphically displayed. $n=5$ independent cultures for each time-point. $D$, Calculated $\mathrm{p} 39$ and p35 mRNA moles per neuron based on known amount of CDNA. $n=4$ independent cultures for each time-point. $A-D,{ }^{*} p<0.05$ (two-way ANOVA and Bonferroni's post test). ${ }^{* *} p<0.01$ (two-way ANOVA and Bonferroni's post test). ${ }^{* * *} p<0.001$ (two-way ANOVA and Bonferroni's post test). n.s., not mide (CHX, $100 \mu \mathrm{g} / \mathrm{ml}$ ) for 0 or $2 \mathrm{~h}$. $\beta$-Actin serves as a loading control. $F$, Top, Representative immunoblot of $(\mathrm{dk} 5$ protein in primary cultured rat cortical neurons. Bottom, Percentage of increase of densitometry readings of $\mathrm{Cdk} 5$ normalized to $\beta$-actin. $n=$ 3 independent cultures for each time-point. One-way ANOVA followed by Tukey's post hoc test was performed.

Loss of p39 attenuates overall Cdk5 activity and differentially affects phosphorylation of Cdk 5 targets in brain neurons

To address the role of endogenous $\mathrm{p} 39$ in activating Cdk5 in brain neurons, we performed acute knockdown of $\mathrm{p} 39$ by siRNA in cultured cortical neurons without affecting p35 or Cdk5 (Fig. 3A), which led to a significant reduction in activity of immunoprecipitated Cdk5 (Fig. 3B). Furthermore, immunoblot analysis using two independent phospho-specific antibodies detected reduction of Cdk5-dependent mode I phosphorylation of microtubuleassociated protein 1B (PI-MAP1B) (Fig. 3C), a key player that controls microtubule dynamics, axonal extension and pathfinding, and dendritic spine formation (Villarroel-Campos and GonzalezBillault, 2014). Interestingly, phosphorylation at S397 of WAVE1 
A

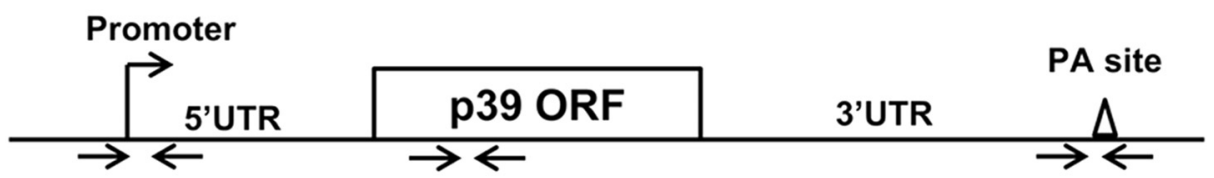

B

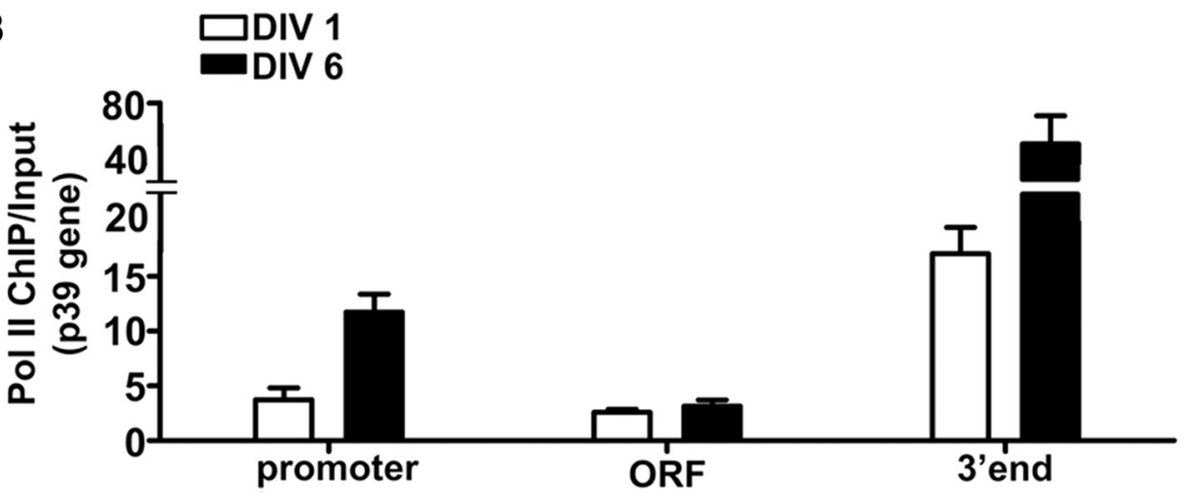

C

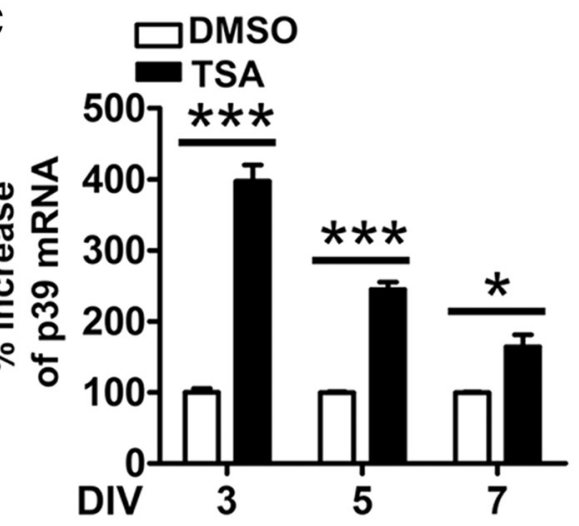

D

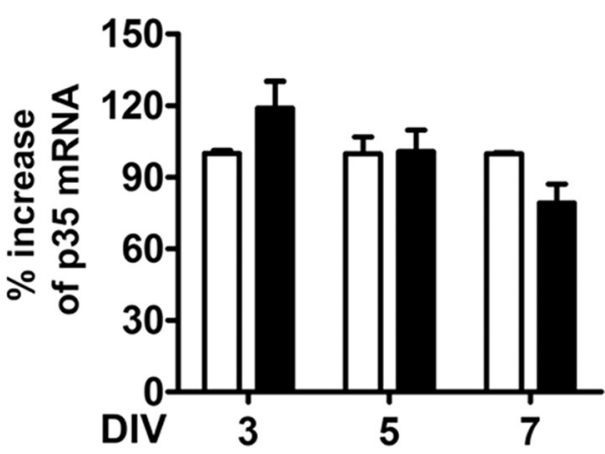

E

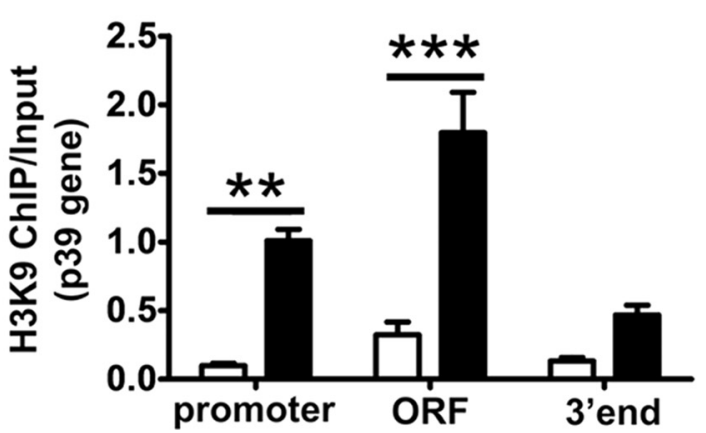

$\mathbf{F}$

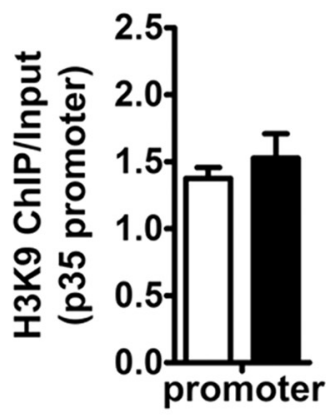

Figure 2. Histone acetylation-dependent transcription upregulates $p 39$ during neuronal differentiation. $A$, Schematic illustration of the $p 39$ gene and PCR primers used for qPCR of genomic DNA crosslinked with RNA Pol II ChIP assay. Open reading frame (ORF), the $5^{\prime}$ and $3^{\prime}$ untranslated region (UTR), and the polyadenylation (PA) site of p 39 are indicated. $\boldsymbol{B}$, Pol II ChIP using primary cultured rat cortical neurons. qPCR readings of genomic DNA in Pol II ChIP were normalized to input. Two-way ANOVA showed a significant effect between DIV1 and DIV6 ( $p=0.03)$. C, D, qRT-PCR quantification of p39 (C) and p35 (D) mRNA in rat cortical neurons following inhibition of histone deacetylases by TSA or mock treatment by DMSO. The percentage of increase caused by TSA compared with the mock control at each DIV is graphically displayed. E, F, ChIP-qPCR on DIV5 rat cortical neurons by an antibody against acetyl-histone 3, lysine 9 (H3K9) following TSA treatment, using $\mathrm{p} 39$ promoter primers $(\boldsymbol{E})$ and $\mathrm{p} 35$ promoter primers $(\boldsymbol{F}) . \boldsymbol{C}-\boldsymbol{E},{ }^{*} p<0.05$ (two-way ANOVA and Bonferroni's post test). ${ }^{* *} p<0.01$ (two-way ANOVA and Bonferroni's post test). ${ }^{* * *} p<0.001$ (two-way ANOVA and Bonferroni's post test). For all experiments, $n=3$ independent cultures were used.

(pWAVE1-S397), a well-recognized functional target of Cdk5 that also plays key roles in synaptic development (Kim et al., 2006), was not significantly affected by $\mathrm{p} 39$ knockdown (Fig. 3D).

To further test whether the loss of p39 affects phosphorylation of Cdk5 targets during neuronal circuitry assembly in vivo, we examined PI-MAP1B in the neonatal hippocampus of $p 39^{-1-}$ mice and wild-type (Wt) controls. Similar to cultured cortical neurons, PI-MAP1B was significantly reduced in the $p 39^{-/-}$hippocampus at the age of P5 and P10 (Fig. $3 E$ ), the time window for hippocampal microcircuit formation (Bagri 
A

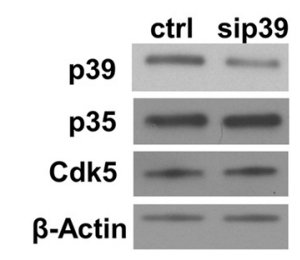

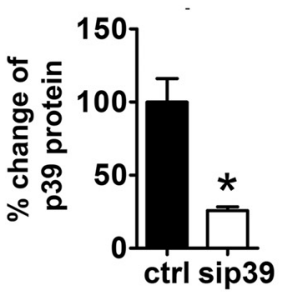

B

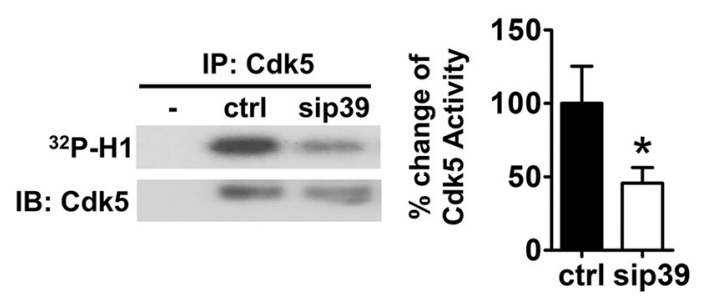

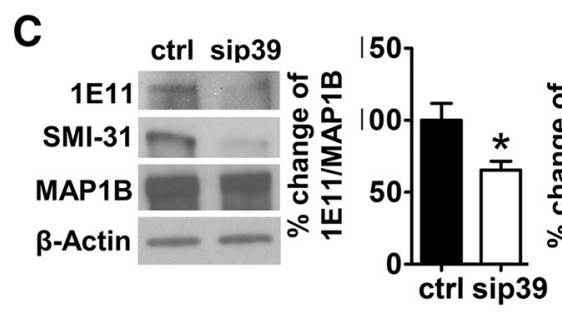

E

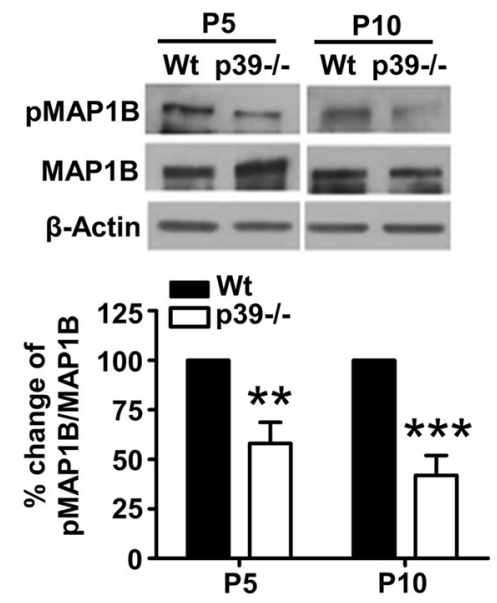

$\mathbf{F}$
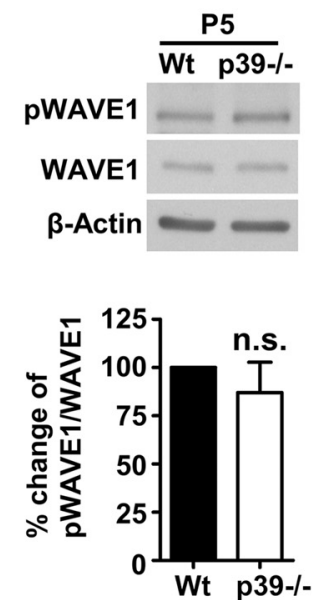

D

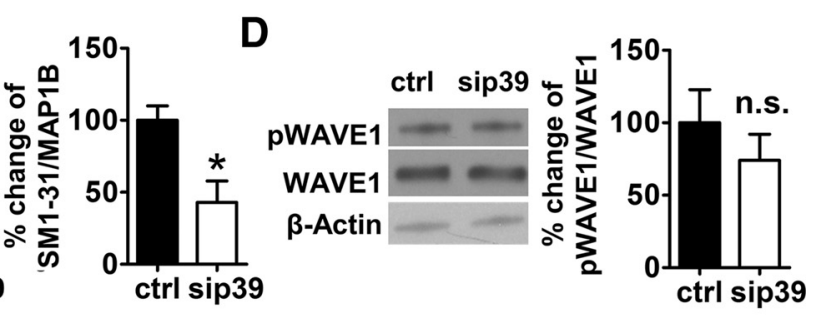

Figure 3. Altered phosphorylation of Cdk5 targets due to $\mathrm{p} 39$ deficiency in cultured cortical neurons and hippocampi in vivo. $A$, Immunoblot of p35, p39, and Cdk5 protein $48 \mathrm{~h}$ after transfection using p39-specific siRNA (sip39) or negative control siRNA (ctrl). Densitometry reading of $\mathrm{p} 39$ is normalized to the $\beta$-actin signal, and the percentage of knockdown is graphically displayed on the right. $n=4$ independent cultures. ${ }^{*} p<0.05$ (Student's $t$ test, with Welch's correction to account for unequal variances). $\boldsymbol{B}$, In vitro kinase assay using Cdk5 complexes immunoprecipitated from DIV 5 rat cortical neurons treated with p39- or ctrl-siRNA and Histone $\mathrm{H} 1$ as the substrate in the presence of $\gamma^{-}{ }^{32} \mathrm{P}$-ATP. Cdk5 activity is calculated by normalizing ${ }^{32} \mathrm{P}$-H1 signal to Cdk5 protein level on immunoblot (left), and is graphically displayed on the right. $n=6$ independent cultures per treatment. $C, D$, Immunoblot of Cdk5 targets upon siRNA knockdown of p39 in cortical neurons. C, PI-MAP1B using two different phospho-specific antibodies (1E11 and SMI-31) and total MAP1B by immunoblot. D, WAVE1-pSer397 and total WAVE1 by immunoblot. E-G, Immunoblot of Cdk5 targets in hippocampi of $p 39^{-1-}$ mice and Wt controls. E, PI-MAP1B and total MAP1B. F, WAVE1-pSer397 and total WAVE1. G, GR1-pSer211 and total GR1. Densitometry reading of each phospho-protein was normalized to the corresponding total protein and graphically displayed on the right $(\boldsymbol{B}-\boldsymbol{D})$ or below $(\boldsymbol{E}-\boldsymbol{G}) . \boldsymbol{C}, \boldsymbol{D}, n=4$ independent cultures per treatment. $\boldsymbol{E}-\boldsymbol{G}, n=4$ mice per genotype, at each indicated age. $\boldsymbol{E}$, Two-way ANOVA and Bonferroni's post test. All other panels were analyzed by the Student's $t$ test: ${ }^{*} p<0.05 ;{ }^{* *} p<0.01 ;{ }^{* * *} p<0.001$. n.S., Not significant at $p>0.05$.

et al., 2003). In contrast, pWAVE1-S397 was unaffected in the p39 $39^{-1-}$ hippocampus (Fig. $3 F$ ). However, MAP1B is diminished to low levels when neuronal arbor formation is completed (Ma et al., 1997), thus making it difficult to perform quantitative analysis in adult brains. To examine Cdk5 targets in the $p 39^{-1-}$ adult brain, we quantified Cdk5-dependent phosphorylation of the glucocorticoid receptor at S211 (pGR1S211) (Kino et al., 2007), which is critical for neuronal longevity (Gräff et al., 2012). As shown in Figure 3G, pGR1-S211was significantly reduced in the $p 39^{-/-}$hippocampus at the age of P48. Neither p35 nor Cdk5 expression levels were affected by the loss of p39 in the neonatal (P5) and adult (P48) hippocampus. Together, these results demonstrate the functional importance of p39 in neuronal Cdk5 activation and target phosphorylation not only during neonatal developing but also in the adult brain.
Essential function of $\mathrm{p} 39$ in advancing axonal development, dendritic spine formation, and synaptogenesis

We next questioned whether p39 is essential for axon development in hippocampal neurons that display a well-defined temporal profile of axonal growth and branching in culture (Dotti et al., 1988). At the peak of rapid axon extension (DIV4), the maximum axon length of $p 39^{-/-}$hippocampal neurons was significantly shorter than Wt controls (Fig. 4A,B). Meanwhile, the number of branches from the primary axon was increased in $p 39^{-1-}$ neurons (Fig. $4 A, C$ ). Consequently, the total length of axon was not significantly altered by the loss of p39 (Fig. 4D). To test whether the loss of p39 affects axonal development in vivo, we examined hippocampal MFs, which are well-characterized axons of dentate granular cells that form synapses with CA3 pyramidal neurons, in $p 39^{-/-}$and Wt mice. Immunostaining of calbindin labels the suprapyramidal bundle (SPB) and infra-pyramidal bundle (IPB) 
A

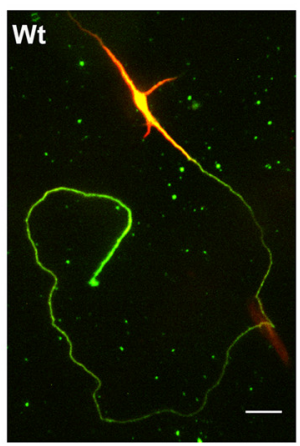

B

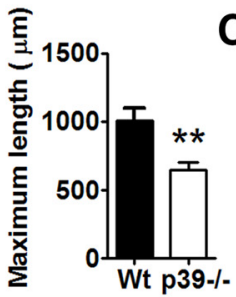

C

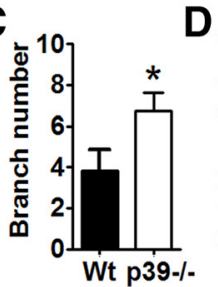

D

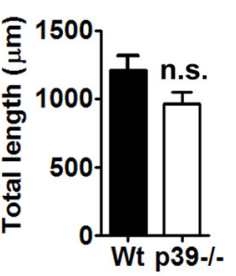

$\mathrm{E}$
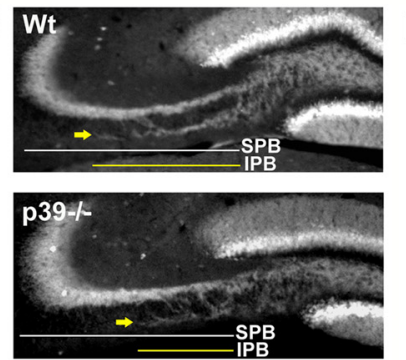

$F$

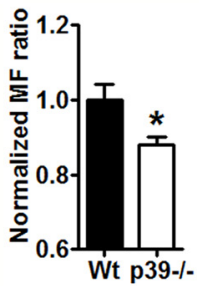

Figure 4. Aberrant axonal development of $p 39^{-/-}$hippocampal neurons in culture and hippocampal MF projection in vivo. $\boldsymbol{A}$, Immunofluorescent staining of TAU (green) and MAP2 (red) label axons and dendrites, respectively, of DIV4 hippocampal neurons derived from Wt or p39 $9^{-1-}$ mice. $\boldsymbol{B}-\boldsymbol{D}$, Quantification of maximal axonal length $(\boldsymbol{B})$, branch number $(\boldsymbol{C})$, and total axonal length $(\boldsymbol{D})$ ( $n=19$ WT neurons and $n=24 \mathrm{p39^{-/- }}$ neurons). $\boldsymbol{E}$, Representative immunofluorescent staining of calbindin labeled hippocampal MF pathway at the age of P10. The IPB and the SPB branch out from the hilus. Arrow indicates the end of IPB. Yellow line below the image indicates the length of IPB. White line indicates the length of SPB. $\boldsymbol{F}$, The length of IPB was normalized to that of SPB and graphically displayed. $n=4$ mice per genotype. ${ }^{*} p<0.05$ (Student's $t$ test). ${ }^{* *} p<0.01$ (Student's $t$ test). n.S., Not significant, $p>0.05$.

of MFs, respectively (Fig. 4E). The relative length of IPB to SPB is a commonly used marker for assessing MF projection during hippocampal microcircuit formation (Bagri et al., 2003). Consistent with the aberrant axonal growth in culture, the relative IPB length was significantly shortened in $p 39^{-/-}$neonates (Fig. $4 F$ ). Together, these data demonstrate that p39-dependent Cdk5 activity is required for proper axonal development of hippocampal neurons in culture and in vivo.

The role of Cdk 5 in controlling dendritic spine density is complex in various biological paradigms (Fu et al., 2007; Su and Tsai, 2011; Lai et al., 2012). To address the function of p39 in intrinsic dendritic spine development, we performed acute siRNA knockdown of p39 in DIV13 hippocampal neurons that undergo robust dendritic spine and synapse formation (Papa et al., 1995). The coexpressed eGFP identified transfected neurons $(\sim 5 \%)$ and provided a volume marker for imaging dendritic spines. p39 knockdown was achieved in distantly separated neurons without affecting nearby presynaptic neurons. As a result, a significant reduction of spine formation was observed due to p39 knockdown in the postsynaptic neuron (Fig. 5A). Expression of Flagtagged human p39 significantly increased spine density in p39-siRNA-treated neurons (Fig. 5B). Furthermore, the density of mature spines labeled by PSD-95 (Fig. 5C) and functional spines that formed synapses labeled by the presynaptic marker SV2 (Fig. 5D) were also reduced by p39 knockdown. These data demonstrate that $\mathrm{p} 39$-mediated Cdk5 activity is essential for dendritic spine and synapse formation.

Dendritic spines are highly dynamic in vivo even after the formation of neuronal circuitry. Hence, we examined whether the loss of p39 affects dendritic spine density in the brain. The Thy-1-YFP-H transgene (The Jackson Laboratory) was introduced into $p 39^{-1-}$ mice and Wt control mice, which allows visualization of dendritic spines from cortical layer $\mathrm{V}$ pyramidal neurons by confocal microscopy in young adults as shown in Figure $5 E$ and $F$. Quantitative analysis revealed a significant reduction of spine density on primary dendritic segments (Fig. $5 E$ ) as well as on apical tuft dendritic segments (Fig. $5 F$ ). These results suggest that the functional requirement of p39 is beyond the initial dendritic spine formation in cultured hippocampal neurons. Rather, p39 seems to act as a common essential factor that advances dendritic spine formation in various types of postnatal brain neurons.

Loss of p39 results in dysregulation of Cdk5 targets at synapses and ameliorated response to pharmacologically induced seizure

Because Cdk5, p35, and p39 are present at synapses (Humbert et al., 2000a), we next questioned how the loss of p39 may affect Cdk5 targets in SNSs isolated from the hippocampus. Interestingly, Cdk5-dependent phosphorylation of synapsin I at site 7 (pSynI-S553 in mouse) (Provenzano et al., 2015), a major player that regulates synaptic vesicle trafficking and neurotransmitter release (Verstegen et al., 2014), was significantly increased in $p 39^{-/-}$SNS (Fig. 6A). In contrast, P1-MAP1B in $p 39^{-/-}$SNS was unaffected (Fig. $6 B$ ). To explore whether and how the loss of p39 cause dysregulation of $\mathrm{p} 35$, which may underlie the aberrantly enhanced phosphorylation of SynI, we examined the full-length p35 and its calpain-dependent cleavage product p25 in SNS (Fig. $6 C$ ). We found that the sum of $\mathrm{p} 35$ and $\mathrm{p} 25$ was increased $\sim 30 \%$ in $p 39^{-/-}$SNS (Fig. $6 D$ ). Notably, a more prompt increase of the full-length p35 was observed (two-fold) (Fig. 6E) concomitant with reduced p25, resulting in a four-fold increase of the p35 to p25 ratio (Fig. 6F). Thus, the loss of p39 leads to not only increased synaptic abundance of $\mathrm{p} 35$ but also reduced $\mathrm{p} 35$ cleavage by calpain. Given the fact that $\mathrm{p} 35$ is associated with membranes at synapses, whereas p 25 is released from the membrane upon p35 cleavage (Minegishi et al., 2010), the reduced cleavage of p35 in $p 39^{-1-}$ SNS is expected to preferentially enhance phosphorylation of Cdk5 targets at the membrane, represented by pSynI-S553.

Considering the involvement of Cdk5 and p35 in epilepsy (Chae et al., 1997; Chen et al., 2000), we explored whether and how the loss of p39 may affect epileptic responses upon KAinduced seizure. Interestingly, unlike the proepileptic phenotype in $p 35^{-/-}$mice (Chae et al., 1997; Patel et al., 2004), $p 39^{-/-}$mice failed to maintain the duration of SE (Fig. $7 A, B$ ) without affecting the latency to SE. Furthermore, the loss of p39 differentially affected expression of activity-induced immediate early genes. As shown in Figure 7C, KA-induction of c-fos mRNA, a commonly used molecular marker for overall neuronal activation (Zhang et al., 2002), was enhanced in the $p 39^{-1-}$ hippocampus in the early phase of SE and maintained at normal levels through the end of the seizure paradigm. In contrast, induction of ARC and BDNF mRNAs, both of which are known to encode proteins that control hippocampal excitatory responses and epileptogenesis (Binder et al., 2001; Shepherd and Bear, 2011), was significantly ameliorated 
in the $p 39^{-/-}$hippocampus (Fig. $7 D, E$ ). These data indicate that $\mathrm{p} 39$ is essential for maintaining behavioral and molecular epileptic responses and further suggest that the functional interplay between p39 and p35 is critical for balancing the proepileptic and antiepileptic roles of Cdk5.

\section{Discussion}

In this study, we discovered that selective upregulation of $\mathrm{p} 39$ is the driving force for increasing Cdk5 activity in postnatal neurons, which accommodates the functional needs of Cdk5 in neuronal arbor formation and synaptogenesis. Furthermore, the complex dysregulation of Cdk5 targets, the aberrant axonal and dendritic spine development, and the failure in maintaining epileptic responses caused by the loss of p39 demonstrate essential roles of p39 in neuronal development and brain function. Hence, our studies have ended the long debate regarding whether p39 is simply a backup of p35 and suggest that p39 and p35 play nonoverlapping roles to achieve balanced Cdk5 function in a normal brain. A working model illustrating the regulation and function of p39-Cdk5 and $\mathrm{p} 35-\mathrm{Cdk} 5$ in postnatal neurons is presented in Figure 8.

Transcriptional upregulation of $\mathrm{p} 39$ is the driving force for enhancing Cdk5 activity in the postnatal brain

The marked upregulation of p39 mRNA and protein in the neonatal hippocampus recapitulates the previously reported increase of p39 mRNA in the cerebral cortex (Takahashi et al., 2003). Furthermore, the robust increase of p39 during cortical neuron differentiation in culture shown in our study, in contrast to the steady expression of $\mathrm{p} 35$, indicates that cellautonomous increase of p39 is commonly used by postnatal forebrain neurons to enhance Cdk5 activity. Mechanistically, histone acetylation at the p39 gene is increased in differentiating neurons, which selectively recruits RNAPol II to enhance p39 transcription. In contrast, histone acetylation at the p35 promoter is maximized. However, unlike the restriction of p39 in the postnatal forebrain, hindbrain regions, including cerebellum, brainstem, and spinal cord, express p39 mRNA during embryonic development (Takahashi et al., 2003). In addition, both $\mathrm{p} 35$ and $\mathrm{p} 39$ proteins decline to low levels 2 weeks after birth in hindbrain regions. Whether neurons in the forebrain and hindbrain may harbor distinct molecular mechanisms to regulate $\mathrm{Cdk} 5$ activator expression is an intriguing possibility to be explored.

A

C

D

$\mathbf{E}$

$\mathbf{F}$
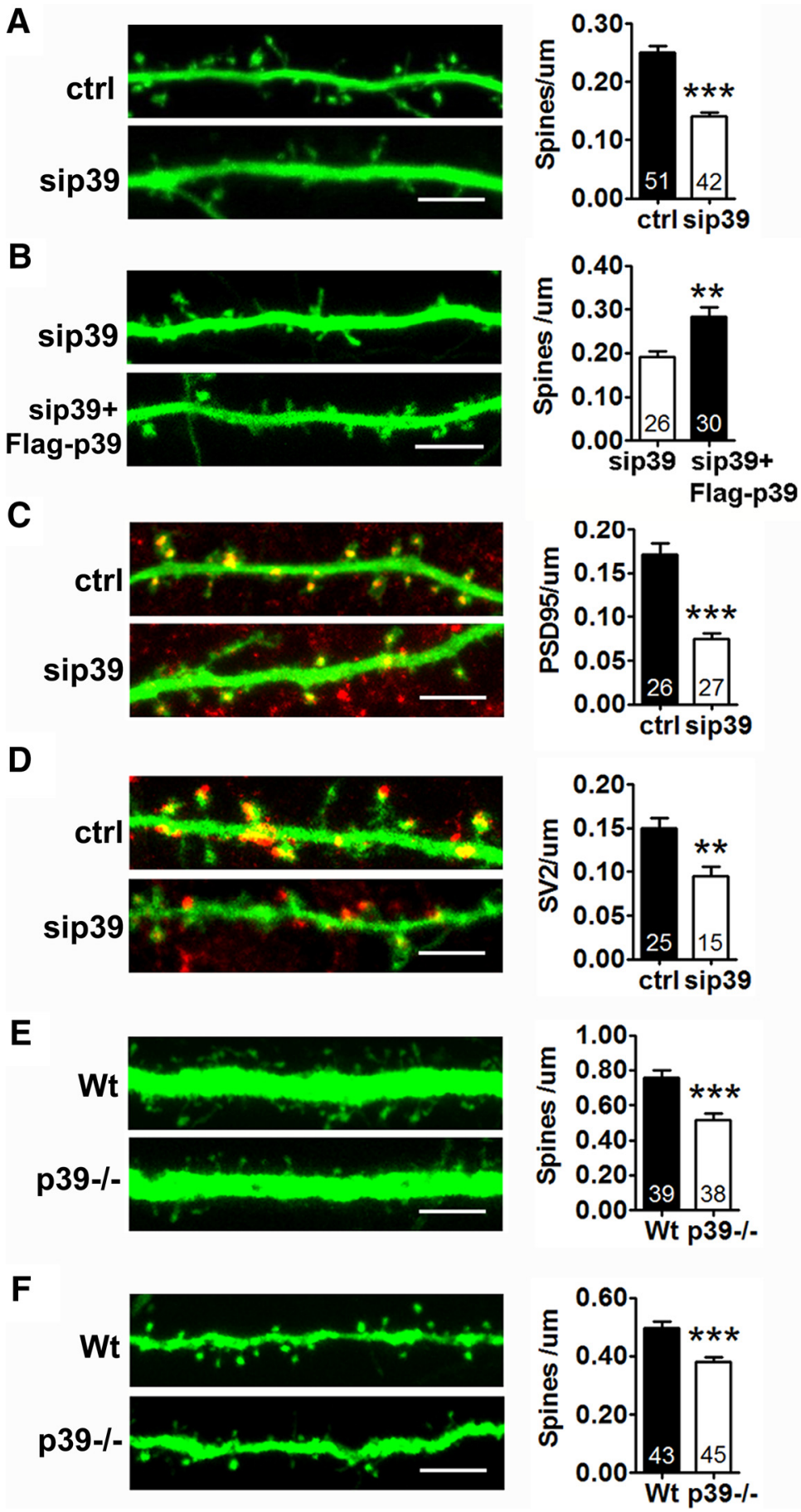

Figure 5. Impairment of dendritic spine and synapse formation upon acute knockdown of p39 in hippocampal neurons. Primary hippocampal neurons were cotransfected with eGFP (green) and control siRNA (ctrl) or p39-siRNA (sip39) $(\boldsymbol{A}, \boldsymbol{C}, \boldsymbol{D})$ and with Flag-p39 (B) at DIV13. At DIV16, confocal imaging of dendritic spine was performed. $\boldsymbol{A}, \boldsymbol{B}, \mathrm{p} 39$ siRNA reduced dendritic spine formation $(\boldsymbol{A})$, which was rescued by the Flag-p39 (B). C, p39 knockdown reduced mature dendritic spines containing PSD95 (red). D, p39 knockdown reduced dendriticspines that form synapses, marked by colocalization of GFP-labeled spines (green) with the presynapticterminal marker SV2 (red). $\boldsymbol{E}, \boldsymbol{F}$, Confocal analysis of dendritic spines marked by Thy1-YFP-H in apical primary dendrites $(\boldsymbol{E})$ and tuft dendrites $(\boldsymbol{F})$ of layer V cortical pyramidal neurons in young adult Wt and $p 39^{-/-}$mice. For each panel, representative images of fluorescently labeled dendritic spines are displayed on the left with calculated spine density shown on the right. Scale bar, $5 \mu \mathrm{m}$. The numbers of dendritic segments analyzed are indicated on the bar graphs. Student's $t$ test was performed for all panels. $\boldsymbol{A}, \boldsymbol{C}^{* *} p<0.01$ (Welch's correction for unequal variances was applied to the $t$ test). ${ }^{* *} p<0.001$ (Welch's correction for unequal variances was applied to the $t$ test).

Notably, p39 is also upregulated to advance OL differentiation. Thus, selective production of p39 is a commonly used means by both neurons and OLs for enhancing Cdk5 activity. Because p39 has a longer half-life than p35 (Minegishi et al., 

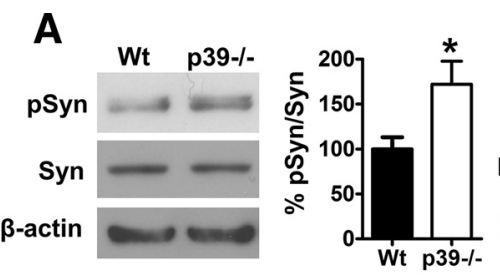

B
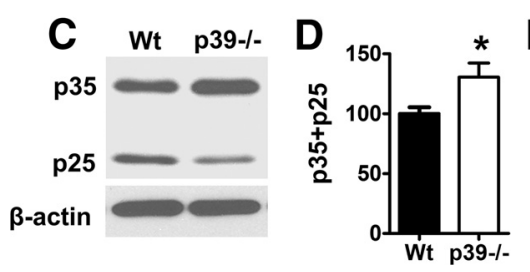

Figure 6. Dysregulation of synaptic Cdk5 targets and 335 in $p 39^{-/-}$hippocampal SNS. A, B Immunoblot of Cdk5-dependent phosphorylation of synapsin I at S533 (pSyn) (A) and PI-MAP1B (B) in SNS isolated from Wt and $p 39^{-/-}$hippocampi. Densitometry reading of each phospho-protein was normalized to the corresponding total protein and graphically displayed on the right. $n=4$ mice per genotype. ${ }^{*} p<0.05$ (Student's $t$ test). C, Immunoblot of $p 35$ and $p 25$ in Wt and $p 39^{-/-}$SNS. D-F, Densitometry

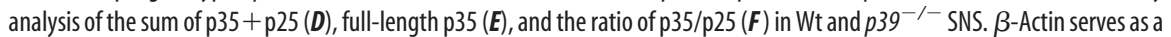
loading control for all experiments. $\boldsymbol{D}-\boldsymbol{F}, n=9$ mice per genotype. ${ }^{*} p<0.05$ (Student's $t$ test with Welch's correction for unequal variances). ${ }^{* *} p<0.01$ (Student's $t$ test with Welch's correction for unequal variances).
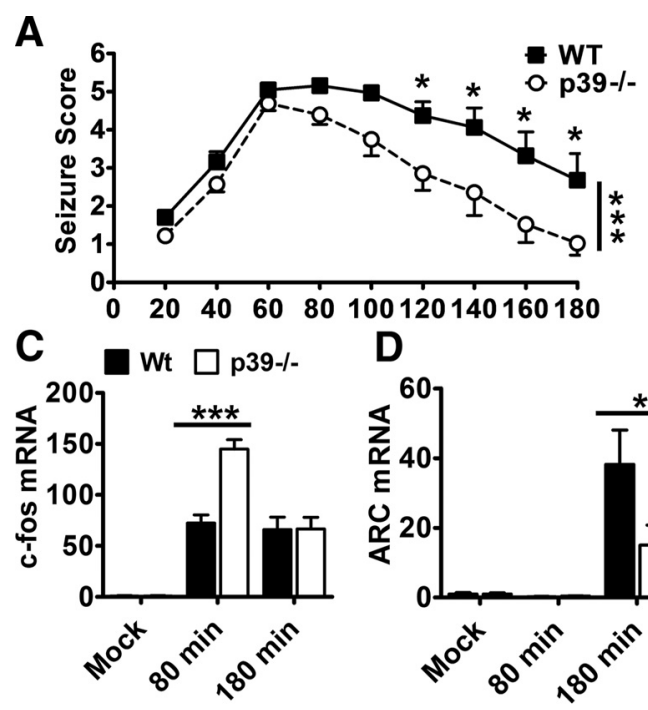

\section{B}
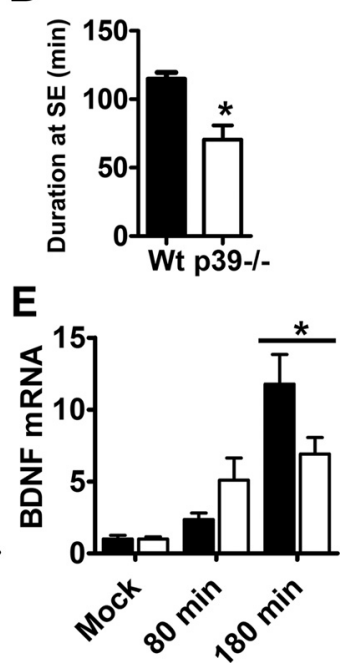

Figure 7. Behavioral and molecular response to KA-induced seizure in $p 39^{-/-}$and Wt mice. $\boldsymbol{A}$, Seizure scores within each 20 min interval were averaged for Wt and $p 39^{-/-}$mice after KA injection ( $n=11$ Wt mice and $n=17 p 39^{-/-}$mice). $\boldsymbol{B}$, Duration of SE, defined as the amount of time spent in SE, in Wt and $p 39^{-/-}$mice. $\boldsymbol{C}-\boldsymbol{E}, \mathrm{qRT}-\mathrm{PCR}$ quantification of c-fos mRNA $(\boldsymbol{C}), A R C$ mRNA $(\boldsymbol{D})$, and BDNF mRNA $(\boldsymbol{E})$. Numbers of mice analyzed in each genotype for qRT-PCR analysis are indicated in Table 2. Two-way ANOVA and Bonferroni's post test were applied for all panels except $\boldsymbol{B}$, where the Student's $t$ test was used. ${ }^{*} p<0.05$. ${ }^{* * *} p<0.001$.

2010), selective upregulation of $\mathrm{p} 39$ provides an advantage for sustained increase of Cdk5 activity in neurons and OLs during postnatal brain development. Moreover, $\mathrm{p} 39$ is more resistant to calpain-dependent proteolytic cleavage than p35 (Minegishi et al., 2010). It is well documented that cleavage of p35 disrupts membrane association of $\mathrm{p} 35$ and the cleavage product p 25 elicits mislocalization and deregulation of Cdk5 activity, which is implicated in a number of human brain diseases represented by Alzheimer's disease and stroke (Lee et al., 2000; Meyer et al., 2014; Seo et al., 2014; Tan et al., 2015). Hence, selective upregulation of p39 in postnatal neurons may better maintain physiological Cdk5 function and limits the deleterious effects by cleavage products of Cdk5 activators upon neuronal insult.
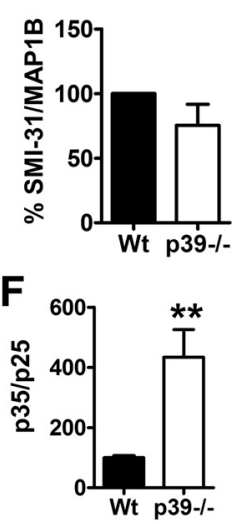

The loss of p 39 causes complex functional consequence on Cdk5 targets

Reduced Cdk5 activity and target phosphorylation upon acute knockdown of p39 in cultured neurons and in $p 39^{-/-}$ hippocampus demonstrate the intrinsic function of p39 in activating Cdk5. The p39-dependent Cdk5 activation is not limited to differentiating neurons but is also important in the adult brain, represented by the phosphorylation of GR1 at S211. Notably, the loss of p39 does not affect specific Cdk5 targets, represented by pWAVE1-S397, a well-documented target of p35-Cdk5 in modulating dendritic spine maturation (Kim et al., 2006). The differential subcellular distribution of p39 and p35 (Minegishi et al., 2010) is a likely underlying mechanism for p39 and p35 to differentially direct Cdk5 to phosphorylate distinct neuronal targets.

In addition to deficiency of p39dependent Cdk5 phosphorylation, the loss of p39 also results in dysregulation of p35 at synapses. The increased p35 abundance and reduced p35 cleavage in the $p 39^{-/-}$SNS led to aberrantly elevated phosphorylation, preferentially of membrane Cdk 5 targets, represented by pSynIS553 that controls the recruitment of resting synaptic vesicles into the recycling pool (Verstegen et al., 2014). The complex phosphorylation changes of Cdk 5 targets caused by p39 deficiency argue that p35- and p39-dependent Cdk5 activation achieves a functional balance, which governs normal brain development and function.

p39 is essential for promoting neuronal network development

Cdk5 phosphorylates numerous proteins crucial for neuronal morphogenesis ( $\mathrm{Su}$ and Tsai, 2011). Inhibition of Cdk5 or elimination of p35 abrogates axon formation (Nikolic et al., 1996; Paglini et al., 1998). We show here that $\mathrm{p} 39$ plays essential roles in governing axonal extension and branching of hippocampal neurons. Thus, p39 and p35 synergistically advance axonal arbor development. Notably, p39 is localized to the distal end of growing neurites (Humbert et al., 2000b). Knockdown of p39, but not p35, abrogates Cdk5-dependent regulation of lamellipodia formation (Ito et al., 2014). The reduced maximal axon length and increased axon branching in $p 39^{-/-}$neurons recapitulate axonal abnormalities in the MAP1B hypomorph mutant due to aberrant microtubule dynamics (Gonzalez-Billault et al., 2001). The abnormal MF projection in $p 39^{-/-}$neonatal hippocampus recapitulates the roles of PI-MAP1B in axonal extension and pathfinding (Villarroel-Campos and Gonzalez-Billault, 2014). Thus, PI-MAP1B is a functional target of p39-Cdk5 in axonal development. In addition, Cdk5/p39 was previously reported to play a 


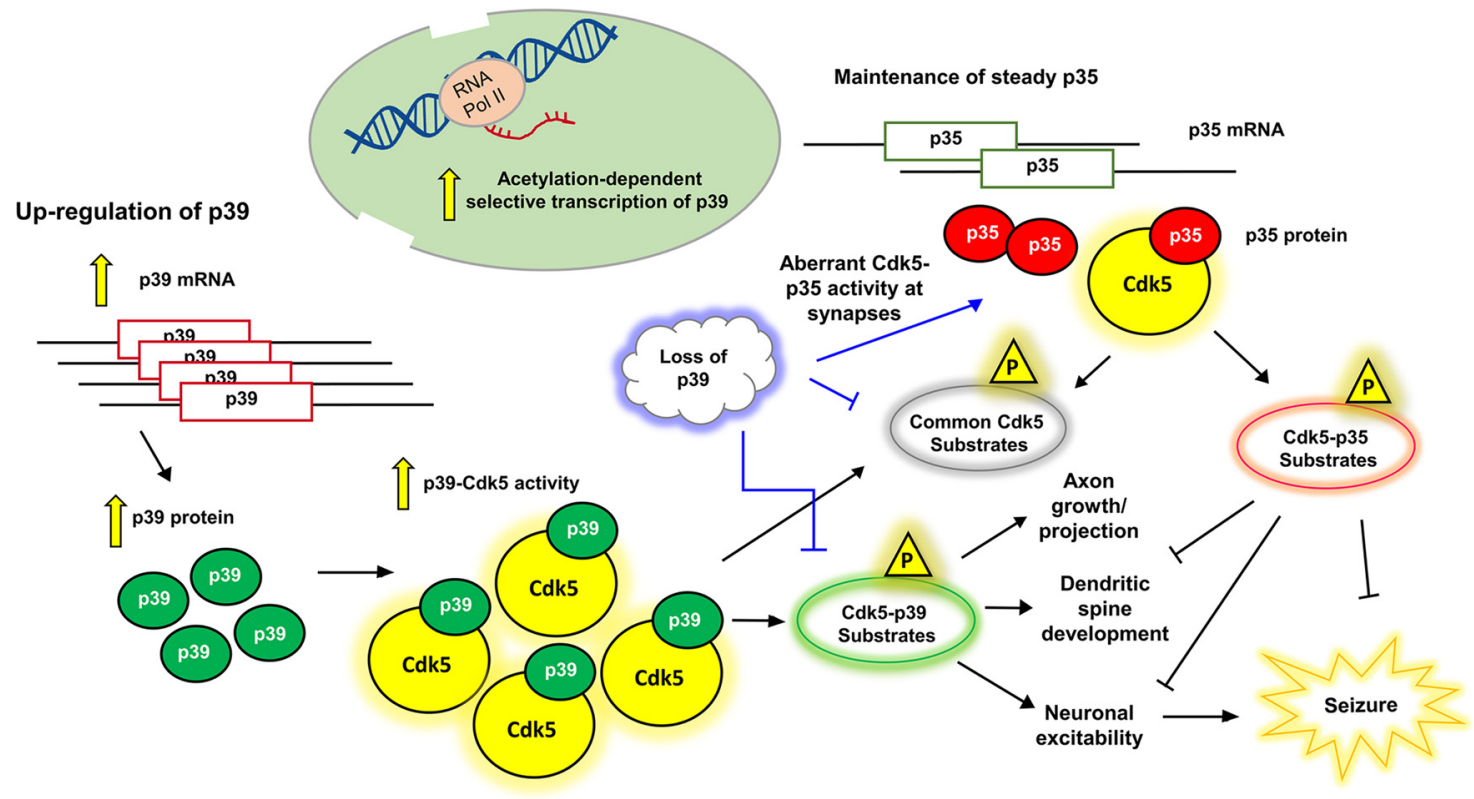

Figure 8. A working hypothesis for functional diversity and cooperation by Cdk5 activators in postnatal brain neurons. Histone acetylation of the p39 locus selectively increases $\mathrm{p} 39$ transcription in neonatal brain neurons, resulting in upregulation of p39 mRNA and protein, whereas p35 abundance is unaltered. Consequently, p39-dependent Cdk5 activation leads to phosphorylation of a subgroup of Cdk5 substrates, which advances axonal and dendritic spine development, governs neuronal excitability, and counteracts the suppressive roles of p35-Cdk5. The loss of p39 causes defects in neuronal network formation and disrupts the balance between the nonoverlapping roles mediated by p35 and p39 in synaptic assembly and activation, leading to reduced seizure responses in $p 39^{-1-}$ mice.

major role in phosphorylating Tau and modulating microtubule binding activity of Tau (Takahashi et al., 2003), which further reinforces the role of $\mathrm{p} 39-\mathrm{Cdk} 5$ in regulating microtubule dynamicity to control axonal development.

The function of Cdk5 in modulating dendritic spine density is complex. Cdk5-dependent phosphorylation of Ephexin1 causes dendritic spine retraction (Kim et al., 2006; Fu et al., 2007). Cdk5p35-dependent phosphorylation of WAVE-1 also negatively regulates dendritic spines in striatal neurons (Kim et al., 2006; Fu et al., 2007; Meyer et al., 2008). Conversely, Cdk5 phosphorylates TrkB, which underlies the activity-dependent increase in spine density and synaptic enlargement (Lai et al., 2012). In addition, inhibition of Cdk5 activity suppresses dendritic spine outgrowth in the nucleus accumbens (Norrholm et al., 2003). We found that p39 governs cell-autonomous dendritic spine formation in cultured hippocampal neurons and layer $\mathrm{V}$ pyramidal neurons in vivo, which likely involve axonal and dendritic cooperation. The differential roles of p39 and p35 in directing Cdk5 to phosphorylate substrates (Tripathi et al., 2015) and the distinct regulation of p35 and p39 in response to histone deacetylase-mediated epigenetic regulation provide a possible explanation of the sophisticated and sometimes opposing functions of Cdk5 in modulating dendritic spine density in various biological paradigms.

\section{Cdk5 activators may play opposing roles to govern neuronal excitability and epileptic responses}

Cdk5 expression is increased in postmortem brains of epilepsy patients (Xi et al., 2009). Additionally, the loss of either Cdk5 or p35 leads to increased seizure susceptibility (Chae et al., 1997; Patel et al., 2004; Takahashi et al., 2010), suggesting that p35 mediates the antiepileptic function of Cdk5. On the other hand, inhibition of Cdk5 activity counteracts KA induced excitotoxicity damages (Putkonen et al., 2011). We found that $p 39^{-/-}$mice fail to maintain SE upon KA-induced seizure, suggesting that p39 may mediate the proepileptic function of Cdk5. The opposing epileptic responses caused by the loss of p35 and p39 suggest a functional balance between $\mathrm{Cdk} 5$ activators in maintaining normal excitability of the neuronal circuitry upon stimulation.

At this point, how the loss of $\mathrm{p} 39$ causes a failure in maintaining SE is undetermined and likely involves multiple mechanisms. The deficit in dendritic spine and synapse formation due to the loss of p39 conceivably contribute to the defects in maintaining neuronal network excitability. In addition, dysregulation of p35 at the $p 39^{-/-}$synapses leads to increased pSynI-S553, a main effector for Cdk5-mediated sequestration of synaptic vesicles into the resting pool and depletion of the recycling pool during longlasting stimulations (Verstegen et al., 2014). Because NMDA receptor activation triggers calpain-dependent cleavage of p35, the reduced p35 cleavage in $p 39^{-/-}$synapses may suggest deficiency of NMDA receptor function, which plays key roles for the maintenance of epilepsy (Chen et al., 2007). Moreover, the loss of p39 selectively ameliorates KA-induced expression of BDNF and ARC, both of which are known to govern hippocampal neuron excitability (Binder et al., 2001; Shepherd and Bear, 2011). The reduced $\mathrm{BDNF}$ induction in $p 39^{-1-}$ brain is consistent with the recent discovery that transcription of BDNF is a target for activity-dependent nuclear function of Cdk5 (Liang et al., 2015) and the observation that p39 is more prone to nuclear translocation than p35 (Asada et al., 2012). Moreover, given the critical function of BDNF-TrkB signaling in epileptogenesis (Binder et al., 2001; Liu et al., 2013), the ameliorated induction of BDNF in $p 39^{-1-}$ likely contributes to the shortened duration of SE.

Together, our studies have uncovered novel means used by neurons to control Cdk5 function through p39 in the postnatal brain. The selective regulation of $\mathrm{p} 39$ during postnatal neuron development and the dysregulation of a subclass of Cdk 5 targets due to the loss of p39 suggest nonoverlapping roles of Cdk5 activators, which may underlie the diverse and sometimes conflicting roles of Cdk5 in modulating brain function. Moreover, our studies provide evidence that argues for the functional interplay be- 
tween p39 and p35, which is crucial for achieving balanced Cdk5 function in postnatal neurons.

\section{References}

Asada A, Saito T, Hisanaga S (2012) Phosphorylation of p35 and p39 by Cdk5 determines the subcellular location of the holokinase in a phosphorylation-site-specific manner. J Cell Sci 125:3421-3429. CrossRef Medline

Bagri A, Cheng HJ, Yaron A, Pleasure SJ, Tessier-Lavigne M (2003) Stereotyped pruning of long hippocampal axon branches triggered by retraction inducers of the semaphorin family. Cell 113:285-299. CrossRef Medline

Banker GA, Cowan WM (1977) Rat hippocampal neurons in dispersed cell culture. Brain Res 126:397-442. CrossRef Medline

Bankston AN, Li W, Zhang H, Ku L, Liu G, Papa F, Zhao L, Bibb JA, Cambi F, Tiwari-Woodruff SK, Feng Y (2013) p39, the primary activator for cyclin-dependent kinase 5 (Cdk5) in oligodendroglia, is essential for oligodendroglia differentiation and myelin repair. J Biol Chem 288:1804718057. CrossRef Medline

Binder DK, Croll SD, Gall CM, Scharfman HE (2001) BDNF and epilepsy: too much of a good thing? Trends Neurosci 24:47-53. CrossRef Medline

Chae T, Kwon YT, Bronson R, Dikkes P, Li E, Tsai LH (1997) Mice lacking p35, a neuronal specific activator of Cdk5, display cortical lamination defects, seizures, and adult lethality. Neuron 18:29-42. CrossRef Medline

Chen J, Zhang Y, Kelz MB, Steffen C, Ang ES, Zeng L, Nestler EJ (2000) Induction of cyclin-dependent kinase 5 in the hippocampus by chronic electroconvulsive seizures: role of [Delta]FosB. J Neurosci 20:8965-8971. Medline

Chen Q, He S, Hu XL, Yu J, Zhou Y, Zheng J, Zhang S, Zhang C, Duan WH, Xiong ZQ (2007) Differential roles of NR2A- and NR2B-containing NMDA receptors in activity-dependent brain-derived neurotrophic factor gene regulation and limbic epileptogenesis. J Neurosci 27:542-552. CrossRef Medline

Dent EW, Barnes AM, Tang F, Kalil K (2004) Netrin-1 and semaphorin 3A promote or inhibit cortical axon branching, respectively, by reorganization of the cytoskeleton. J Neurosci 24:3002-3012. CrossRef Medline

Dotti CG, Sullivan CA, Banker GA (1988) The establishment of polarity by hippocampal neurons in culture. J Neurosci 8:1454-1468. Medline

Fan Y, Tang X, Vitriol E, Chen G, Zheng JQ (2011) Actin capping protein is required for dendritic spine development and synapse formation. J Neurosci 31:10228-10233. CrossRef Medline

Fu WY, Chen Y, Sahin M, Zhao XS, Shi L, Bikoff JB, Lai KO, Yung WH, Fu AK, Greenberg ME, Ip NY (2007) Cdk5 regulates EphA4-mediated dendritic spine retraction through an ephexin1-dependent mechanism. Nat Neurosci 10:67-76. CrossRef Medline

Gonzalez-Billault C, Avila J, Cáceres A (2001) Evidence for the role of MAP1B in axon formation. Mol Biol Cell 12:2087-2098. CrossRef Medline

Gräff J, Rei D, Guan JS, Wang WY, Seo J, Hennig KM, Nieland TJ, Fass DM, Kao PF, Kahn M, Su SC, Samiei A, Joseph N, Haggarty SJ, Delalle I, Tsai LH (2012) An epigenetic blockade of cognitive functions in the neurodegenerating brain. Nature 483:222-226. CrossRef Medline

Hawasli AH, Benavides DR, Nguyen C, Kansy JW, Hayashi K, Chambon P, Greengard P, Powell CM, Cooper DC, Bibb JA (2007) Cyclindependent kinase 5 governs learning and synaptic plasticity via control of NMDAR degradation. Nat Neurosci 10:880-886. CrossRef Medline

Hotulainen P, Llano O, Smirnov S, Tanhuanpää K, Faix J, Rivera C, Lappalainen P (2009) Defining mechanisms of actin polymerization and depolymerization during dendritic spine morphogenesis. J Cell Biol 185: 323-339. CrossRef Medline

Humbert S, Lanier LM, Tsai LH (2000a) Synaptic localization of p39, a neuronal activator of cdk5. Neuroreport 11:2213-2216. CrossRef Medline

Humbert S, Dhavan R, Tsai L (2000b) p39 activates cdk5 in neurons, and is associated with the actin cytoskeleton. J Cell Sci 113:975-983. Medline

Ito Y, Asada A, Kobayashi H, Takano T, Sharma G, Saito T, Ohta Y, Amano M, Kaibuchi K, Hisanaga S (2014) Preferential targeting of p39activated Cdk5 to Rac1-induced lamellipodia. Mol Cell Neurosci 61:3445. CrossRef Medline

Kim Y, Sung JY, Ceglia I, Lee KW, Ahn JH, Halford JM, Kim AM, Kwak SP, Park JB, Ho Ryu S, Schenck A, Bardoni B, Scott JD, Nairn AC, Greengard P (2006) Phosphorylation of WAVE1 regulates actin polymerization and dendritic spine morphology. Nature 442:814-817. CrossRef Medline
Kino T, Ichijo T, Amin ND, Kesavapany S, Wang Y, Kim N, Rao S, Player A, Zheng YL, Garabedian MJ, Kawasaki E, Pant HC, Chrousos GP (2007) Cyclin-dependent kinase 5 differentially regulates the transcriptional activity of the glucocorticoid receptor through phosphorylation: clinical implications for the nervous system response to glucocorticoids and stress. Mol Endocrinol 21:1552-1568. CrossRef Medline

Ko J, Humbert S, Bronson RT, Takahashi S, Kulkarni AB, Li E, Tsai LH (2001) p35 and p39 are essential for cyclin-dependent kinase 5 function during neurodevelopment. J Neurosci 21:6758-6771. Medline

Koch CM, Andrews RM, Flicek P, Dillon SC, Karaöz U, Clelland GK, Wilcox S, Beare DM, Fowler JC, Couttet P, James KD, Lefebvre GC, Bruce AW, Dovey OM, Ellis PD, Dhami P, Langford CF, Weng Z, Birney E, Carter NP, et al. (2007) The landscape of histone modifications across $1 \%$ of the human genome in five human cell lines. Genome Res 17:691-707. CrossRef Medline

Lai KO, Wong AS, Cheung MC, Xu P, Liang Z, Lok KC, Xie H, Palko ME, Yung WH, Tessarollo L, Cheung ZH, Ip NY (2012) TrkB phosphorylation by Cdk5 is required for activity-dependent structural plasticity and spatial memory. Nat Neurosci 15:1506-1515. CrossRef Medline

Lee MS, Kwon YT, Li M, Peng J, Friedlander RM, Tsai LH (2000) Neurotoxicity induces cleavage of p35 to p25 by calpain. Nature 405:360-364. CrossRef Medline

Liang Z, Ye T, Zhou X, Lai KO, Fu AK, Ip NY (2015) Cdk5 regulates activitydependent gene expression and dendrite development. J Neurosci 35: 15127-15134. CrossRef Medline

Liu G, Gu B, He XP, Joshi RB, Wackerle HD, Rodriguiz RM, Wetsel WC, McNamara JO (2013) Transient inhibition of TrkB kinase after status epilepticus prevents development of temporal lobe epilepsy. Neuron 79: 31-38. CrossRef Medline

Ma D, Nothias F, Boyne LJ, Fischer I (1997) Differential regulation of microtubule-associated protein 1B (MAP1B) in rat CNS and PNS during development. J Neurosci Res 49:319-332. CrossRef Medline

Maynard KR, Stein E (2012) DSCAM contributes to dendrite arborization and spine formation in the developing cerebral cortex. J Neurosci 32: 16637-16650. CrossRef Medline

Meyer DA, Richer E, Benkovic SA, Hayashi K, Kansy JW, Hale CF, Moy LY, Kim Y, O'Callaghan JP, Tsai LH, Greengard P, Nairn AC, Cowan CW, Miller DB, Antich P, Bibb JA (2008) Striatal dysregulation of Cdk5 alters locomotor responses to cocaine, motor learning, and dendritic morphology. Proc Natl Acad Sci U S A 105:18561-18566. CrossRef Medline

Meyer DA, Torres-Altoro MI, Tan Z, Tozzi A, Di Filippo M, DiNapoli V, Plattner F, Kansy JW, Benkovic SA, Huber JD, Miller DB, Greengard P, Calabresi P, Rosen CL, Bibb JA (2014) Ischemic stroke injury is mediated by aberrant Cdk5. J Neurosci 34:8259-8267. CrossRef Medline

Minegishi S, Asada A, Miyauchi S, Fuchigami T, Saito T, Hisanaga S (2010) Membrane association facilitates degradation and cleavage of the cyclindependent kinase 5 activators p35 and p39. Biochemistry 49:5482-5493. CrossRef Medline

Ng T, Ryu JR, Sohn JH, Tan T, Song H, Ming GL, Goh EL (2013) Class 3 semaphorin mediates dendrite growth in adult newborn neurons through Cdk5/FAK pathway. PLoS One 8:e65572. CrossRef Medline

Nikolic M, Dudek H, Kwon YT, Ramos YF, Tsai LH (1996) The cdk5/p35 kinase is essential for neurite outgrowth during neuronal differentiation. Genes Dev 10:816-825. CrossRef Medline

Norrholm SD, Bibb JA, Nestler EJ, Ouimet CC, Taylor JR, Greengard P (2003) Cocaine-induced proliferation of dendritic spines in nucleus accumbens is dependent on the activity of cyclin-dependent kinase-5. Neuroscience 116:19-22. CrossRef Medline

Paglini G, Pigino G, Kunda P, Morfini G, Maccioni R, Quiroga S, Ferreira A, Cáceres A (1998) Evidence for the participation of the neuron-specific CDK5 activator P35 during laminin-enhanced axonal growth. J Neurosci 18:9858-9869. Medline

Papa M, Bundman MC, Greenberger V, Segal M (1995) Morphological analysis of dendritic spine development in primary cultures of hippocampal neurons. J Neurosci 15:1-11. Medline

Patel LS, Wenzel HJ, Schwartzkroin PA (2004) Physiological and morphological characterization of dentate granule cells in the p35 knock-out mouse hippocampus: evidence for an epileptic circuit. J Neurosci 24: 9005-9014. CrossRef Medline

Perez de Arce K, Varela-Nallar L, Farias O, Cifuentes A, Bull P, Couch BA, Koleske AJ, Inestrosa NC, Alvarez AR (2010) Synaptic clustering of 
PSD-95 is regulated by c- $\mathrm{Abl}$ through tyrosine phosphorylation. J Neurosci 30:3728-3738. CrossRef Medline

Provenzano G, Pangrazzi L, Poli A, Sgadò P, Berardi N, Bozzi Y (2015) Reduced phosphorylation of synapsin I in the hippocampus of Engrailed-2 knockout mice, a model for autism spectrum disorders. Neuroscience 286: 122-130. CrossRef Medline

Putkonen N, Kukkonen JP, Mudo G, Putula J, Belluardo N, Lindholm D, Korhonen L (2011) Involvement of cyclin-dependent kinase-5 in the kainic acid-mediated degeneration of glutamatergic synapses in the rat hippocampus. Eur J Neurosci 34:1212-1221. CrossRef Medline

Rojas A, Gueorguieva P, Lelutiu N, Quan Y, Shaw R, Dingledine R (2014) The prostaglandin EP1 receptor potentiates kainate receptor activation via a protein kinase $C$ pathway and exacerbates status epilepticus. Neurobiol Dis 70:74-89. CrossRef Medline

Seo J, Giusti-Rodríguez P, Zhou Y, Rudenko A, Cho S, Ota KT, Park C, Patzke H, Madabhushi R, Pan L, Mungenast AE, Guan JS, Delalle I, Tsai LH (2014) Activity-dependent p25 generation regulates synaptic plasticity and Abeta-induced cognitive impairment. Cell 157:486-498. CrossRef Medline

Shepherd JD, Bear MF (2011) New views of Arc, a master regulator of synaptic plasticity. Nat Neurosci 14:279-284. CrossRef Medline

Soden ME, Chen L (2010) Fragile X protein FMRP is required for homeostatic plasticity and regulation of synaptic strength by retinoic acid. J Neurosci 30:16910-16921. CrossRef Medline

Stuss DP, Boyd JD, Levin DB, Delaney KR (2012) MeCP2 mutation results in compartment-specific reductions in dendritic branching and spine density in layer 5 motor cortical neurons of YFP-H mice. PLoS One 7:e31896. CrossRef Medline

Su SC, Tsai LH (2011) Cyclin-dependent kinases in brain development and disease. Annu Rev Cell Dev Biol 27:465-491. CrossRef Medline

Takahashi S, Saito T, Hisanaga S, Pant HC, Kulkarni AB (2003) Tau phosphorylation by cyclin-dependent kinase 5/p39 during brain development reduces its affinity for microtubules. J Biol Chem 278:10506-10515. CrossRef Medline
Takahashi S, Ohshima T, Hirasawa M, Pareek TK, Bugge TH, Morozov A, Fujieda K, Brady RO, Kulkarni AB (2010) Conditional deletion of neuronal cyclin-dependent kinase 5 in developing forebrain results in microglial activation and neurodegeneration. Am J Pathol 176:320-329. CrossRef Medline

Tan X, Chen Y, Li J, Li X, Miao Z, Xin N, Zhu J, Ge W, Feng Y, Xu X (2015) The inhibition of Cdk5 activity after hypoxia/ischemia injury reduces infarct size and promotes functional recovery in neonatal rats. Neuroscience 290:552-560. CrossRef Medline

Tripathi BK, Lowy DR, Zelenka PS (2015) The Cdk5 activator P39 specifically links muskelin to myosin II and regulates stress fiber formation and actin organization in lens. Exp Cell Res 330:186-198. CrossRef Medline

Tsai LH, Delalle I, Caviness VS Jr, Chae T, Harlow E (1994) p35 is a neuralspecific regulatory subunit of cyclin-dependent kinase 5. Nature 371: 419-423. CrossRef Medline

Verstegen AM, Tagliatti E, Lignani G, Marte A, Stolero T, Atias M, Corradi A, Valtorta F, Gitler D, Onofri F, Fassio A, Benfenati F (2014) Phosphorylation of synapsin I by cyclin-dependent kinase- 5 sets the ratio between the resting and recycling pools of synaptic vesicles at hippocampal synapses. J Neurosci 34:7266-7280. CrossRef Medline

Villarroel-Campos D, Gonzalez-Billault C (2014) The MAP1B case: an old MAP that is new again. Dev Neurobiol 74:953-971. CrossRef Medline

Xi ZQ, Xiao F, Yuan J, Wang XF, Wang L, Quan FY, Liu GW (2009) Gene expression analysis on anterior temporal neocortex of patients with intractable epilepsy. Synapse 63:1017-1028. CrossRef Medline

Yamada M, Saito T, Sato Y, Kawai Y, Sekigawa A, Hamazumi Y, Asada A, Wada M, Doi H, Hisanaga S (2007) Cdk5-p39 is a labile complex with the similar substrate specificity to Cdk5-p35. J Neurochem 102:14771487. CrossRef Medline

Ye T, Fu AK, Ip NY (2012) Cyclin-dependent kinase 5 in axon growth and regeneration. Int Rev Neurobiol 105:91-115. CrossRef Medline

Zhang J, Zhang D, McQuade JS, Behbehani M, Tsien JZ, Xu M (2002) c-fos regulates neuronal excitability and survival. Nat Genet 30:416-420. CrossRef Medline 